\title{
4
}

\section{Focal Cortical Presentations Genetically Proven Alzheimer Disease}

\author{
Naeije G et al. ${ }^{1}$ \\ Department of Neurology, Hôpital Erasme \\ Université Libre de Bruxelles, Brussels \\ Belgium
}

\section{Introduction}

The term Alzheimer Disease (AD) was first proposed by the famous German psychiatrist, Emil Kraepelin, over a century ago, in the eighth edition of his textbook of psychiatry. AD was, at this time, included in the differential diagnosis of presenile dementia. Kraeppelin chose this name to honor one of his pupils Aloïs Alzheimer who was one of the first to describe the pathological pattern that hallmarks the disease $(1,2)$ : miliary foci of extracellular structures (senile plaque) and the intracellular flame-shaped fiberlike bundles (tangles) observed in the brain of a fifty years old woman who presented with dementia and delusions he had first clinically followed (figure 1, copyright-free).

For decades, the term AD was used for patients whose onset of dementia was before 65 years old. In 1977, it was admitted that physiopathological changes were the same whatever was the age of clinical illness begining (3). The classic clinical pattern consists in early episodic memory loss followed by a various combination of higher function modalities alterations (executive, language, visuo-spatial impairment...) reflecting the spread of the pathology from the medio-temporal lobe to other neo-cortical areas $(4,5)$. Thus, actual diagnostic criteria for AD (NINCDS-ADRDA and DSM IV) claim that the disease is probable if there are cognitive impairments in two or more areas of cognition, whether memory and one other (aphasia, apraxia, agnosia or executive dysfunctions for DSM-IV) or two from the following eight: memory, language, perceptual skills, attention, constructive abilities, orientation, problem solving and functional abilities for NINCDS-ADRDA. Assuming that the deficits were progressive for both, the onset between 40 and 90 years old for NINCDADRDA and that disease masquerading AD were excluded. Against neuropathological gold

\footnotetext{
Van den Berge Delphine ${ }^{2}$, Vokaer $\mathrm{M}^{1}$, Fery $\mathrm{P}^{2}$, Vilain $\mathrm{C}^{3}$, Abramowicz $\mathrm{M}^{3}$, Van den Broeck $\mathrm{M}^{4,5,6,}$ Van Broeckhoven $\mathrm{C}^{4,5,6}$ and Bier $\mathrm{JC}^{1}$

1 Department of Neurology, Hôpital Erasme, Université Libre de Bruxelles; Brussels, Belgium

2 Department of Neuropsychology, Hôpital Erasme, Université Libre de Bruxelles; Brussels, Belgium

3 Clinical genetics, Hopital Erasme, Université Libre de Bruxelles; Brussels, Belgium

4 Neurodegenerative Brain Diseases Group, Department of Molecular Genetics, VIB, Antwerpen, Belgium

5 Laboratory of Neurogenetics, Institute Born-Bunge, Antwerpen, Belgium

6 University of Antwerp, Antwerpen, Belgium
} 
standards, the accuracy of those criteria is low: $65-96 \%$ and their specificity against other dementias even lower $23-88 \%(6,7,8)$. Furthermore, these criteria impose the necessity of presenting dementia to make a diagnosis of AD. Howhever, it is very clear today that such disease begins to express itself well before the presence of dementia. Thus, focal cortical presentation of $\mathrm{AD}$ escapes diagnostic by those criteria whether because memory loss remains isolated like in isolated progressive amnesia (IPA), amnesic mild cognitive impairment (MCI) or because the presenting feature that involves an other area of cognition than memory like in posterior cortical atrophy, semantic dementia, primary progressive aphasia, etc...

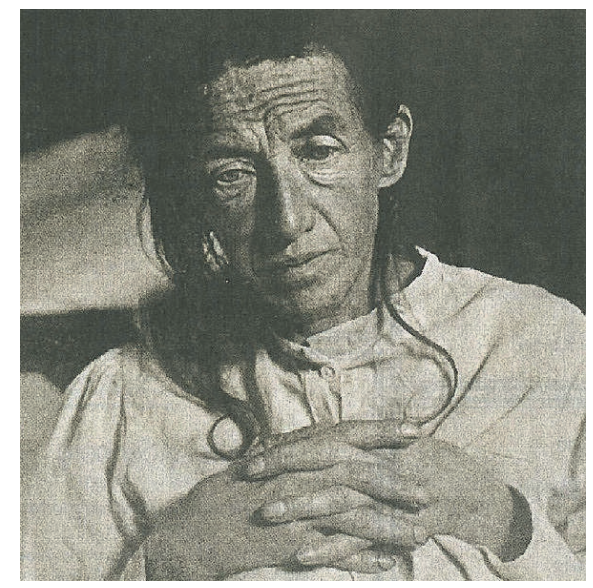

The senile plaque found in the hippocampus, temporal cortex and the nucleus basalis of Meynert of patient suffering from AD are made of a core of $\mathrm{A} \beta$-amyloid, proteoglycans, ApoE, antichimotrypsin and other proteins. $A \beta$-amyloid is a protein derived proteolytically from a larger transmembrane protein: amyloid precursor protein (APP). The cleavage of APP is processed either in a non amyloidogenic way in a two step manner by the action of an $\alpha$-followed by the action of $\gamma$-secretase and lead to the production of the non toxic P3 peptide. The amyloidogenic way is due to the action of a $\beta$-secretase in toxic A $\beta 42$ and lesstoxic A $\beta 40$. Three genes have been associated with autosomal dominant AD, the APP gene, the Presenilin 1 (PSEN1) gene that codes for a protease that is part of the $\gamma$-secretase complex and Presenilin2 (PSEN2) that is also part of the $\gamma$-secretase complex (9).

Actually, those three genes can be screened for $\mathrm{AD}$ and are estimated to be responsible for $0.5 \%$ of all $\mathrm{AD}$ and $13 \%$ of early onset $\mathrm{AD}$.

According to the Alzheimer Disease \& Frontotemporal Dementia Mutation Database (http://www.molgen.ua.ac.be/ADMutations), of the EOFAD mutations identified, PSEN1 mutations account for the majority (81\%), followed by APP (14\%) and with PSEN2 mutations identified only in a handful of families (6\%). An earlier age of onset is linked to the presence of an APOE $\varepsilon 4$ allele and is also sought in suspected genetic AD $(10,11)$.

The second pathological finding in $\mathrm{AD}$ are neurofibrillary tangles. These tangles are filamentous inclusions in neurons that are mostly made of an hyperphosphorylated and aggregated form of $\tau \mathrm{au}$. The normal $\tau \mathrm{au}$ is soluble and favors vesical transport in axons by promoting assembly and stability of microtubules. Abnormal accumulation of the hyperphosphorylated and insoluble form of $\tau$ au is toxic and can be found in several 
neurodegenerative disorders including $\mathrm{AD}$. In $\mathrm{AD}$, The number of tangles is a marker of the disease's severity.

Recently, cerebro-spinal fluid (CSF) biomarkers (12), iconographic $(13,14)$ and metabolic markers $(15,16,17)$ have been validated as supportive criteria for the diagnostic of AD and cases of pathogenic mutations have been described in the preseniline genes in patients presenting with focal cortical presentation of AD. New approaches challenge NINCDSARDA and DSM IV criteria, notably the criteria proposed by Dubois et al in $2007(18,19)$ that include brain imaging, CSF biomarkers and genetic considerations.

In this chapter, we will present two patients with new mutations in the PSEN 1 gene for one, APP gene for the other and isolated cognitive loss in both cases. We will discuss the various presentation of focal cortical presentation of $\mathrm{AD}$ and try to broaden the new criteria of Dubois et al to fit those presentations.

\section{Cases- reports}

\subsection{Isolated progressive amnesia (IPA) associated with the London mutation of the APP (20)}

A fifty year old, right handed salesman consulted for memory deficits, he first noticed five years before. The trouble began by subjective blunders in his professional activities as forgetting to collect information from his customers that increased and eventually cost him his job. His medical history was unremarkable except for a road accident 43 years before without loss of consciousness. Interestingly, his family history was significant for personality and memory disorders in his mother, grandmother and maternal aunt who required institutionalization in their early sixties. Neurological examination was within normal limits and his Minimal Mental State Examination (MMSE) score was 28/30. Blood analysis and electroencephalogram didn't reveal any abnormalities. Brain MRI was normal. Extensive neuropsychological examination highlighted an isolated deficit in verbal learning. Visual analysis of his cerebral 2-fluoro-2-deoxy-D-glucose (FDG)-PET obtained at this stage showed slight cortical hypometabolism on temporal tips. Those findings coupled with positive family history and early age of onset prompted us to perform direct sequencing on AD genes, namely of exons 16 and 17 of APP, exons 3 to 12 of PSEN1 and exons 9 to 13 of microtubule associated protein Tau. The analyses lead to the discovery of the London mutation (Val717Ile) in the APP gene that was reported in several autosomal dominant AD families. The clinical evolution was remarkable for the initial striking stability of the isolated progressive amnesia (IPA). Such long lasting IPA is not unheard, a case of 13 years duration IPA was found on autopsy to have pathological AD anomalies and there are reports of atypical $\mathrm{AD}$ preceded by years of isolated amnesia. This case shows that IPA can be a variant of genetically proven $\mathrm{AD}$. Yet this case, even with the genetic analysis would not have fulfilled the NINCDS-ADRDA or DSM IV criteria (20).

\subsection{Progressive non fluent aphasia and executive disturbances associated with a Gly266Cys mutation in PSEN1 (unpublished data)}

A 56 years old physiotherapist consulted with her daughter for gradual-onset speech difficulties over a year. She never presented space or time disorientation nor had important behavioural changes. The core complaint was trouble to find words and effortful speech output due to loss of proper and common nouns. She was still working but felt increasing psychological tension due to her communication problems. Her familial history was 
unremarkable, her mother died of cancer without cognitive impairment at 75 and her father is still alive and alert at 83 years old. Neurological examination was normal. She presented dyscalculia and her MMSE was 28/30, losing one point for sentence rehearsal and one for making a mistake in "world" spelling. Complete neuropsychological examination showed a mixed pattern dominated by dysexecutive and loss of speech production features and saliently a complete lack of episodic memory deficit. The initial diagnostic hypothesis was a predominantly logopenic form of primary progressive aphasia (PPA). Biological work-up was unremarkable. Brain MRI showed a discrete cortical atrophy and FDG-Pet highlighted slight biparietal cortex hypometabolism. Genetic testing was undertaken and positive for a heterozygous mutation in PSEN1 gene never reported before. The mutation in exon 8 implicated an amino acid substitution of Glycine to Cysteine at codon 266. The mutation was absent in 500 belgian controls and mutation in the codon 267 are associated with Early onset $\mathrm{AD}$ in polish and English families which make us think that the mutation is pathogenic in our patient. Furthermore our patient improved with treatment by memantine chlorhydrate. As in our previous case of IPA, this patient would not have fulfilled the actual criteria for AD.

\section{Other focal cortical forms of $A D$}

Classical AD is diagnosed in vivo thanks to criteria centred on memory loss as the first and predominant complaint. Patients presenting with features masquerading other forms of neurodegenerative diseases like PPA, fronto-temporal dementia (FTD), Cortico-Basal Dementia (CBD) can be overlooked. An important study by Alladi et al sought to confront pathological examination with focal cortical syndromes and found that AD was the primarily pathological diagnosis in $34 \%$ of the cases (21). Interestingly, the proportion of focal cortical syndromes associated to AD pathology was different according to their clinical presentations. One hundred percent of posterior cerebral atrophy (PCA) was found to be due to $\mathrm{AD}$ whereas $50 \%$ of CBD, $36 \%$ of PPA and $7 \%$ of FTD were associated with AD pathologies.

We will develop in the following paragraphs the clinical features of those focal cortical presentations.

\subsection{Behavioural variant}

The initial case reported by Aloïs Alzheimer, Auguste D. (figure 1, copyright-free), presented with behavioural disorders, psychosis and delusions in combination with dementia... and had the pathologic anomalies that now hallmark AD. Yet behavioural presentation are not considered in NINCDS-ADRDA and DSM IV criteria and are even an exclusion feature in recently proposed Dubois et al criteria. The behavioural variant of FTD (bv-FTD) is the most common differential diagnosis of AD presenting with behavioural pattern, especially in presenile dementia. bv-FTD is the most common clinical manifestation of FTD that represents one of the seconds causes of cortical dementia after Alzheimer's disease (22). Initial symptoms in bv-FTD patients usually include progressive personality and social conduct changes coupled with executive functions deficits $(23,24)$. Changes in personality, loss of social abilities, apathy, reduced empathy, stereotypic behaviour, disinhibition are in correlation with predominantly orbito-basal and dorsolateral frontal atrophy found on MRI (22). Many studies tried to find distinctive neuropsychological 
patterns or CSF biomarkers that could reliably make the difference between AD and bvFTD. However, pathological studies continue to demonstrate an important proportion of mistakes.

\subsection{Progressive aphasia}

Losing words, especially proper names, may be the first complaint of patients and may thus bring them to consultations. Later, difficulties classically involve common nouns and progress to points where fluency of speech could be seriously impaired. Every sentence can be broken by pauses and search for wanted words. If not found, circumlocutions can be substituted or sentences left unfinished. Depending on which modality of aphasia is mostly affected, PPA is separated in progressive non-fluent aphasia (PNFA) when effortful speech and phonological and/or syntaxic errors is prominent, semantic dementia (SD) (26) and more recently by logopenic aphasia. In SD, speech fluency is preserved but there is a striking anomia, impaired word comprehension and deficits in non-verbal semantic association tasks such as sorting and grouping objects on basis of functional characteristics (26). In logopenic aphasia, repetition is more affected. The localization of semantic memories is usually lateralized. Left parietal and temporal lobes store verbal-language semantic memories whereas the right parietal and temporal and parietal lobes store predominantly visual-spatial semantic memories. These modalities seem to be electively affected in semantic dementia $(26,27)$.

\subsection{Corticobasal syndromes (CBS)}

The term corticobasal dementia was coined to describe a specific nosologic form of corticalsubcortical degenerative disorders. Patients classically present with an asymmetric apraxia and extrapyramidal syndromes with rigidity, bradykinesia and tremor indicating basalganglionic impairment (28). This is usually combined with an "alien hand" phenomena suggesting cortical involvement: the patient, though able to exert normal muscle strength, fail to direct voluntary action, the affected limb is unable to produce purposeful action and attempts result in inappropriate movement. The limb may remain in an odd posture without the patient's awareness; there is some kind of hemisensory neglect and visuospatial impairment. Myoclonus may also be present and may acquire a sensitive stimulus myoclonus pattern as the disease progresses. Initially the disease begins with one limb and then progresses to the other side and to cranial nerves. Apraxia of gaze and eyelids opening are frequent. CBS are considered distinct of $\mathrm{AD}$ for localized thalamoparietal metabolic asymmetries and lack of histopathologic hallmarks on autopsies. Yet, as time passes, most pathological changes associated with dementia have been described: usually tangles, amyloid deposits and lewy bodies. In the Alladi et al study, half of CBS had pathological hallmarks of AD (21) and several mutations of PSEN-1 have been described with clinical extrapyramidal syndromes and myoclonies $(29,30)$.

\subsection{Posterior cortical atrophy (PCA)}

Initial manifestations are characterised by progressive visual impairment. Patients even usually consult an ophtalmologist for reading or driving difficulties. Features of Balint's syndrome can be found such as simultagnosia (patients see the tree instead of the forest), ocular apraxia (inability to direct gaze accurately) and optic ataxia (an object cannot be 
reached by visual guidance). Both simultagnosia and ocular apraxia lead to obvious reading difficulties (31). Visuo-spatial orientation becomes defective. Patients are thus unable to park a car. Their arms do not find correct sleeves of the dressing gown. The route from one place to another cannot be described nor can been understood. PCA can be further subsided in biparietal syndrome, where object recognition and reading are preserved but with marked apraxia, agraphia and visuo-spatial difficulties. Occipito-temporal syndrome presented with alexia, aperceptive agnosia and some degree of prosopagnosia. In visual variants, there is a primary visual failure and failure of perceptual abilities (32). The immense majority of the patients with PCA do have AD with lewy body disease, prion disease, and taupathies as major differential diagnosis (21). The patient in the seminal description of Aloïs Alzheimer, Auguste D, could maybe presented initially with PCA explaining partially precocity of delusions described.

\subsection{Others (myoclonia, cerebellar...)}

Studies of the clinical characteristics of families with mutations in PSEN-1 show wide phenotypic features variety. Ranging from families in which myoclonus and seizures were prominent to ataxia attributed to some cerebellar pathology. Interestingly, extrapyramidal signs were reported in some series in as much as $50 \%$ of patients with PSEN- 1 mutations (29) and seizures in over $20 \%$ PSEN-2 mutations (33).

\section{Recents Dubois et al criteria and our proposed amendements}

In some way, the situation of focal cortical presentation of $\mathrm{AD}$ can be compared to the diagnosis of clinically isolated syndrome in multiple sclerosis (MS). To speak of MS, amnestic, clinical and paraclinical examination must reveal objective anormalities that implicate two or more areas of the central nervous system. If the anomaly is isolated, waiting for another anomaly is mandatory to confirm the diagnostic. This pitfall is responsible for time loss and thus of psychological and physical burden for the patient and in some cases, the worsening of his prognosis. Therefore, in MS, there has been considerable efforts to include paraclinical features in diagnostic criteria to reduce time to diagnosis. Since several years, Central Nervous System MRI, CSF markers and evoked potentials are important features to increase the suspicion of the diagnosis. The same situation happens with actual criteria proposed for AD diagnosis. In cases where there is only an isolated cortical dysfunction without memory impairment or isolated memory impairment without other cortical areas involvement, a diagnosis would be postponed until some new features are added to the pattern. Contrary to MS, where evidenced of diagnosis can be gathered from many clinical or paraclinical sources, actual criteria of $\mathrm{AD}$ fail to consider the knowledge that has been accumulating for years in the field of brain imaging and discoveries of relatively reliable CSF biomarkers. Recently, Dubois et al concerned by the situation proposed their new criteria (Table 1) to replace those previous (from 1984) of the NINCDS-ADRDA (18). The argumentation behind the new criteria is that the previous NINCDS-ADRDA/DSM IV-TR ones were not including recent progresses of imaging and biomarkers for AD. This would be responsible for a low sensibility and sensitivity that could be much improved with the inclusion of CSF analysis, structural MRI and neuroilmaging with PET features. Those additions would lead to more accurate detection of the earliest stages of the disease and of its full spectrum. 
Probable AD:

A plus one or more supportive features $B, C, D$ or $E$

A. Presence of an early and significant episodic memory impairment that includes the following features:

1. Gradual and progressive change in memory function reported by patients or informants over more than 6 months

2. Objective evidence of significantly impaired episodic memory on testing: this generally consists of recall deficit that does not improve significantly or does not normalise with cueing or recognition testing and after effective encoding of information has been previously controlled

3. The episodic memory impairment can be isolated or associated with other cognitive changes at the onset of $\mathrm{AD}$ or as $\mathrm{AD}$ advances

Supportive features

B. Presence of medial temporal lobe atrophy

- Volume loss of hippocampi, entorhinal cortex, amygdala evidenced on MRI with qualitative ratings using visual scoring (referenced to well characterised population with age norms) or quantitative volumetry of regions of interest (referenced to well characterised population with age norms)

C. Abnormal cerebrospinal fluid biomarker

- Low amyloid $A \beta_{1-42}$ concentrations, increased total $\tau$ au concentrations, or increased phospho- $\tau$ au concentrations, or combinations of the three

- Other well validated markers to be discovered in the future

D. Specific pattern on functional neuroimaging with PET

- Reduced glucose metabolism in bilateral temporal parietal regions

- Other well validated ligands, including those that foreseeably will emerge such as Pittsburg compound B or FDDNP

E. Proven AD autosomal dominant mutation within the immediate family

Exclusion criteria

History

- Sudden onset

- Early occurrence of the following symptoms: gait disturbances, seizures, behavioural changes

Clinical features

- Focal neurological features including hemiparesis, sensory loss, visual field deficits

- $\quad$ Early extrapyramidal signs

Other medical disorders severe enough to account for memory and related symptoms

- Non-AD dementia

- Major depression

- Cerebrovascular disease

- Toxic and metabolic abnormalities, all of which may require specific investigations

- MRI FLAIR or T2 signal abnormalities in the medial temporal lobe that are 


\section{consistent with infectious or vascular insults}

Criteria for definite $A D$

AD is considered definite if the following are present:

- Both clinical and histopathological (brain biopsy or autopsy) evidence of the disease, as required by the NIA-Reagan criteria for the post-mortem diagnosis of $\mathrm{AD}$; criteria must both be present

- Both clinical and genetic evidence (mutation on chromosome 1, 14, or 21) of AD; criteria must both be present.

Dubois et al remain focused on early episodic memory impairment as core diagnostic criteron. The degradation of memory function must have started progressively and for over six month. Memory complaints can come from the patient itself or a close relative as both situations are associeted with high risk of developping $\mathrm{AD}(34,35)$. When the complaint is reported, objective memory testing must confirm an impaired delayed recall that is not normalised with cuing or recognition testing. Some studies found that delayed recall was a reliable predictor for $\mathrm{AD}$ in patients with $\mathrm{MCI}$. Memory impairment can be isolated or associated with other cognitive changes.

The inclusion of objective paraclinic tests as supporive features is, we believe, the important inovation of proposions of Dubois et al. They include findings from structural MRI, abnormal CSF markers, specific pattern on functionnal imaging and genetic that are questionnably absents from the previous NINCDS-ADRDA/DSM IV-TR criteria. Unfortunately, their exclusion criteria are actually quite strict. We guess that for a high specifity of their criteria, they choose not to consider any atypical pattern, excluding patients presenting with predominantly behavioural changes, extrapyramidal signs, sensory loss, visual fields deficits. As a consequence, all the AD focal cortical presentations exposed before would fail to qualify for probable AD except for IPA. The 2 cases we here report and other studies examining post-mortem brain pathologies from patient with alleged CBS or focal cortical presentations clearly argue against such exclusion criteria. Yet, it is our belief that with slight modifications, the score proposed by Dubois et al could encompass "atypical-AD". The major modification we thus propose (table 2) is to get free of the memory impairment dogma in AD.

We do not question the fact that most $A D$ begin with episodic impairment and that accumulation of pathologenic almyloid plaques and tangle preferentially starts from the medio-temporal lobe to spread towards other neo-cortical areas. Yet, a significant proportion of patients presents initially with alterations of other cortical skills, even if they represent a small part of all AD. As the prevalence of $\mathrm{AD}$ is high and the population is getting old, this small part of a high population will make many thousands of patients to fail to be diagnosed. Changing episodic memory impairment as core criteria to any gradual cortical impairment with the supportive feature listed by Dubois et al would support a diagnosis of probable AD in most of these cases. We also think that early occurence of gait disturbances, behavioural changes, sensory loss, visual field deficits and extrapyramidal signs should not be exclusion criterias. There is a risk to diminish our specificty to diagnosis by using those amended criteria, but the active searching for supportive features wether genetic, CSF biomarkers or iconographic will help to diagnose early many patients and perhaps help to broaden visions more and more many people have of the AD clinical spectrum. 
Probable AD:

A plus one or more supportive features $B, C, D$ or $E$

A. Presence of an early and significant episodic memory impairment that includes the following features:

1. Gradual and progressive change in any cognitive function reported by patients or informants over more than 6 months

2. Objective evidence of significantly impaired at least this higher function on testing: in case of memory, this generally consists of recall deficit that does not improve significantly or does not normalise with cueing or recognition testing and after effective encoding of information has been previously controlled

3. The cognitive function impairment can be isolated or associated with other cognitive changes at the onset of $\mathrm{AD}$ or as $\mathrm{AD}$ advances

Supportive features

B. Presence of predominantly medial temporal lobe atrophy

- Volume loss of hippocampi, entorhinal cortex, amygdala evidenced on MRI with qualitative ratings using visual scoring (referenced to well characterised population with age norms) or quantitative volumetry of regions of interest (referenced to well characterised population with age norms)

C. Abnormal cerebrospinal fluid biomarker

- Low amyloid $A \beta_{1-42}$ concentrations, increased total $\tau$ au concentrations, or increased phospho- $\tau$ au concentrations, or combinations of the three

- Other well validated markers to be discovered in the future

D. Specific pattern on functional neuroimaging with PET

- $\quad$ Reduced glucose metabolism in bilateral temporal parietal regions

- Other well validated ligands, including those that foreseeably will emerge such as Pittsburg compound B or FDDNP

E. Proven AD autosomal dominant mutation within the immediate family

Exclusion criteria

History

- Sudden onset

- Early occurrence of the following symptoms: gait disturbances, seizures, behavioural changes

Clinical features

- Focal neurological features including hemiparesis, sensory loss, visual field deficits

- Early extrapyramidal signs

Other medical disorders severe enough to account for the cognitive decline and related symptoms

- Non-AD dementia

- Major depression

- Cerebrovascular disease

- Toxic and metabolic abnormalities, all of which may require specific investigations

- MRI FLAIR or T2 signal abnormalities in the medial temporal lobe that are 
consistent with infectious or vascular insults

Criteria for definite $A D$

AD is considered definite if the following are present:

- Both clinical and histopathological (brain biopsy or autopsy) evidence of the disease, as required by the NIA-Reagan criteria for the post-mortem diagnosis of AD; criteria must both be present

- Both clinical and genetic evidence (mutation on chromosome 1, 14, or 21) of AD; criteria must both be present.

\section{References}

[1] Alzheimer A (1907). "Über eine eigenartige Erkrankung der Hirnrinde [About a peculiar disease of the cerebral cortex]" (in (German)). Allgemeine Zeitschrift fur Psychiatrie und Psychisch-Gerichtlich Medizin 64 (1-2): 146-148

[2] Kraepelin E, Diefendorf AR (translated by) (2007-01-17). Clinical Psychiatry: A Textbook For Students And Physicians (Reprint). Kessinger Publishing. p. 568

[3] Katzman Robert, Terry Robert D, Bick Katherine L (editors) (1978). Alzheimer's disease: senile dementia and related disorders. New York: Raven Press. p. 595

[4] Brun A, Englund E (1981). Regional pattern of degeneration in Alzheimer's disease: neuronal loss and histopathological grading. Histopathology 5 (5): 549-564

[5] Braak H, Braak E (1991). Neuropathological stageing of Alzheimer-related changes. Acta Neuropathol 82 (4): 239-259

[6] Lim A, Tsuang D, Kukull W, Nochlin D, Leverenz J, McCormick W, Bowen J, Teri L, Thompson J, Peskind ER, Raskind M, Larson EB (1999). Clinico-neuropathological correlation of Alzheimer's disease in a community-based case series. J Am Geriatr Soc 47 (5): 564-569

[7] Varma AR, Snowden JS, Lloyd JJ, Talbot PR, Mann DM, Neary D (1999). Evaluation of the NINCDS-ADRDA criteria in the differentiation of Alzheimer's disease and frontotemporal dementia. J Neurol Neurosurg Psychiatry 66 (2): 184-188

[8] Kazee AM, Eskin TA, Lapham LW, Gabriel KR, McDaniel KD, Hamill RW (1993). Clinicopathologic correlates in Alzheimer disease: assessment of clinical and pathologic diagnostic criteria. Alzheimer Dis Assoc Disord 7 (3): 152-164

[9] Querfurth HW, LaFerla FM (2010). Alzheimer's disease. N Engl J Med 362 (4): 329-344. Review. Erratum in: (2011) N Engl J Med 364 (6): 588.

[10] Bird TD (2008). Genetic aspects of Alzheimer disease. Genet Med 10 (4): 231-239. 11/ Ertekin-Taner N (2007). Genetics of Alzheimer's disease: a centennial review. Neurol Clin 25 (3): 611-667

[11] Blennow K, Hampel H, Weiner M, Zetterberg H (2010). Cerebrospinal fluid and plasma biomarkers in Alzheimer disease. Nat Rev Neurol 6 (3): 131-144

[12] Van de Pol LA, Hensel A, Barkhof F, Gertz HJ, Scheltens P, van der Flier WM (2006). Hippocampal atrophy in Alzheimer disease: age matters. Neurology 66 (2): 236-238

[13] Wahlund LO, Julin P, Johansson SE, Scheltens P (2000). Visual rating and volumetry of the medial temporal lobe on magnetic resonance imaging in dementia: a comparative study. J Neurol Neurosurg Psychiatry 69 (5): 630-635 
[14] Patwardhan MB, McCrory DC, Matchar DB, Samsa GP, Rutschmann OT (2004). Alzheimer disease: operating characteristics of PET--a meta-analysis. Radiology 231 (1): $73-80$

[15] Albin RL, Koeppe RA, Burke JF, Giordani B, Kilbourn MR, Gilman S, Frey KA (2010). Comparing fludeoxyglucose F18-PET assessment of regional cerebral glucose metabolism and [11C]dihydrotetrabenazine-PET in evaluation of early dementia and mild cognitive impairment. Arch Neurol 67 (4): 440-446

[16] Koeppe RA, Gilman S, Joshi A, Liu S, Little R, Junck L, Heumann M, Frey KA,

[17] Albin RL (2005). 11C-DTBZ and 18F-FDG PET measures in differentiating dementias. J Nucl Med 46 (6): 936-944

[18] Dubois B, Feldman HH, Jacova C, Dekosky ST, Barberger-Gateau P, Cummings J, Delacourte A, Galasko D, Gauthier S, Jicha G, Meguro K, O'brien J, Pasquier F, Robert P, Rossor M, Salloway S, Stern Y, Visser PJ, Scheltens P (2007). Research criteria for the diagnosis of Alzheimer's disease: revising the NINCDS-ADRDA criteria. Lancet Neurol 6 (8): 734-746

[19] Dubois B, Feldman HH, Jacova C, Cummings JL, Dekosky ST, Barberger-Gateau P, Delacourte A, Frisoni G, Fox NC, Galasko D, Gauthier S, Hampel H, Jicha GA, Meguro K, O'Brien J, Pasquier F, Robert P, Rossor M, Salloway S, Sarazin M, de Souza LC, Stern Y, Visser PJ, Scheltens P (2010). Revising the definition of Alzheimer's disease: a new lexicon. Lancet Neurol 9 (11): 1118-1127

[20] Gankam Kengne F, Vokaer M, Fery P, Abramowicz M, Massat I, Van den Broeck M, Van Broeckhoven C, Bier JC (2009). Pure progressive amnesia as variant of genetically proven Alzheimer disease. Eur J Neurol 16 (2): e9-10.

[21] Alladi S, Xuereb J, Bak T, Nestor P, Knibb J, Patterson K, Hodges JR (2007). Focal cortical presentations of Alzheimer's disease. Brain 130 (Pt10): 2636-2645

[22] Piguet O, Hornberger M, Mioshi E, Hodges JR (2011). Behavioural-variant frontotemporal dementia: diagnosis, clinical staging, and management. Lancet Neurol 10 (2): 162-172

[23] Rahman S, Sahakian BJ, Hodges JR, Rogers RD, Robbins TW (1999). Specific cognitive deficits in mild frontal variant frontotemporal dementia. Brain $122(\mathrm{Pt}$ 8): 1469-1493

[24] Torralva T, Roca M, Gleichgerrcht E, Bekinschtein T, Manes F (2009). A neuropsychological battery to detect specific executive and social cognitive impairments in early frontotemporal dementia. Brain 132 (Pt 5): 1299-1309

[25] Gorno-Tempini ML, Hillis AE, Weintraub S, Kertesz A, Mendez M, Cappa SF, Ogar JM, Rohrer JD, Black S, Boeve BF, Manes F, Dronkers NF, Vandenberghe R, Rascovsky K, Patterson K, Miller BL, Knopman DS, Hodges JR, Mesulam MM, Grossman M (2011). Classification of primary progressive aphasia and its variants. Neurology 76 (11): 1006-1014

[26] Nestor PJ, Graham KS, Bozeat S, Simons JS, Hodges JR (2002). Memory consolidation and the hippocampus: further evidence from studies of autobiographical memory in semantic dementia and frontal variant frontotemporal dementia. Neuropsychologia 40 (6): 633-654

[27] Rogalski EJ, Mesulam MM. Clinical trajectories and biological features of primary progressive aphasia (PPA) (2009). Curr Alzheimer Res 6 (4): 331-336

[28] Ludolph AC, Kassubek J, Landwehrmeyer BG, Mandelkow E, Mandelkow EM, Burn DJ, Caparros-Lefebvre D, Frey KA, de Yebenes JG, Gasser T, Heutink P, Höglinger 

- The Charge Toward Comprehensive Diagnostic and Therapeutic Strategies

G, Jamrozik Z, Jellinger KA, Kazantsev A, Kretzschmar H, Lang AE, Litvan I, Lucas JJ, McGeer PL, Melquist S, Oertel W, Otto M, Paviour D, Reum T, Saint-Raymond A, Steele JC, Tolnay M, Tumani H, van Swieten JC, Vanier MT, Vonsattel JP, Wagner S, Wszolek ZK; Reisensburg Working Group for Tauopathies With Parkinsonism (2009). Tauopathies with parkinsonism: clinical spectrum, neuropathologic basis, biological markers, and treatment options. Eur J Neurol 16 (3): 297-309

[29] Larner AJ, Doran M (2006). Clinical phenotypic heterogeneity of Alzheimer's disease associated with mutations of the presenilin-1 gene. J Neurol 253 (2): 139-158

[30] Larner AJ, Doran M (2009). Genotype-phenotype relationships of presenilin-1 mutations in Alzheimer's disease: an update. J Alzheimers Dis 17 (2): 259-265

[31] Levine DN, Lee JM, Fisher CM (1993). The visual variant of Alzheimer's disease: a clinicopathologic case study. Neurology 43 (2): 305-313

[32] McMonagle P, Deering F, Berliner Y, Kertesz A (2006). The cognitive profile of posterior cortical atrophy. Neurology 66 (3): 331-338

[33] Yu CE, Marchani E, Nikisch G, Müller U, Nolte D, Hertel A, Wijsman EM, Bird TD (2010). The N141I mutation in PSEN2: implications for the quintessential case of Alzheimer disease. Arch Neurol 67 (5): 631-633

[34] Geerlings MI, Jonker C, Bouter LM, Adèr HJ, Schmand B (1999). Association between memory complaints and incident Alzheimer's disease in elderly people with normal baseline cognition. Am J Psychiatry 156 (4): 531-537

[35] Tierney MC, Szalai JP, Snow WG, Fisher RH (1996). The prediction of Alzheimer disease. The role of patient and informant perceptions of cognitive deficits. Arch Neurol 53 (5): 423-427 


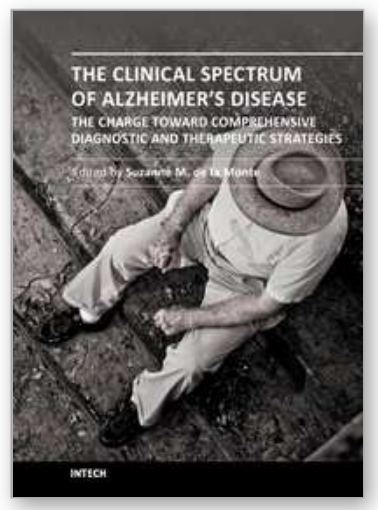

\section{The Clinical Spectrum of Alzheimer's Disease -The Charge Toward Comprehensive Diagnostic and Therapeutic Strategies}

Edited by Dr. Suzanne De La Monte

ISBN 978-953-307-993-6

Hard cover, 362 pages

Publisher InTech

Published online 06, September, 2011

Published in print edition September, 2011

The Clinical Spectrum of Alzheimer's Disease: The Charge Toward Comprehensive Diagnostic and Therapeutic Strategies is highly informative and current. Acknowledged experts in the field critically review both standard and under-appreciated clinical, behavioral, epidemiological, genetic, and neuroimaging attributes of Alzheimer's disease. The collection covers diverse topics of interest to clinicians and researchers alike. Experienced professionals and newcomers to the field will benefit from the read. The strengths and weaknesses of current clinical, non-invasive, neuro-imaging, and biomarker diagnostic approaches are explained. The perspectives give fresh insights into the process of neurodegeneration. Readers will be enlightened by the evidence that the neural circuits damaged by neurodegeneration are much broader than conventionally taught, suggesting that Alzheimer's could be detected at earlier stages of disease by utilizing multi-pronged diagnostic approaches. This book inspires renewed hope that more effective treatments could be developed based upon the expanding list of potential therapeutic targets.

\section{How to reference}

In order to correctly reference this scholarly work, feel free to copy and paste the following:

Naeije G, Van den Berge Delphine, Vokaer M, Fery P, Vilain C, Abramowicz M, Van den Broeck M, Van Broeckhoven C and Bier JC (2011). Focal Cortical Presentations Genetically Proven Alzheimer Disease, The Clinical Spectrum of Alzheimer's Disease -The Charge Toward Comprehensive Diagnostic and Therapeutic Strategies, Dr. Suzanne De La Monte (Ed.), ISBN: 978-953-307-993-6, InTech, Available from: http://www.intechopen.com/books/the-clinical-spectrum-of-alzheimer-s-disease-the-charge-towardcomprehensive-diagnostic-and-therapeutic-strategies/focal-cortical-presentations-genetically-provenalzheimer-disease

\section{INTECH}

open science | open minds

\author{
InTech Europe \\ University Campus STeP Ri \\ Slavka Krautzeka 83/A \\ 51000 Rijeka, Croatia \\ Phone: +385 (51) 770447 \\ Fax: +385 (51) 686166 \\ www.intechopen.com
}

\author{
InTech China \\ Unit 405, Office Block, Hotel Equatorial Shanghai \\ No.65, Yan An Road (West), Shanghai, 200040, China \\ 中国上海市延安西路65号上海国际贵都大饭店办公楼 405 单元 \\ Phone: +86-21-62489820 \\ Fax: +86-21-62489821
}


(C) 2011 The Author(s). Licensee IntechOpen. This chapter is distributed under the terms of the Creative Commons Attribution-NonCommercialShareAlike-3.0 License, which permits use, distribution and reproduction for non-commercial purposes, provided the original is properly cited and derivative works building on this content are distributed under the same license. 